\title{
A primary signet ring cell carcinoma of the prostate with bone metastasis with impressive response to FOLFOX and Cetuximab
}

\author{
Ana Milena Roldán ${ }^{1}$, Natalia Fernández Núñez ${ }^{1}$, Enrique Grande ${ }^{2}$, Augusto \\ Álvarez García ${ }^{3}$, Luis M. Antón-Aparicio ${ }^{1,4}$ \\ 1 Clinical Oncology Department, A Coruña University Hospital, A Coruña, Spain \\ 2 Clinical Oncology Department, Ramón y Cajal University Hospital, Madrid, Spain \\ 3 Pathology Department, A Coruña University Hospital, A Coruña, Spain \\ 4 Medicine Department, A Coruña University, A Coruña, Spain
}

\section{Clinical Practice Points}

- A 65-year-old man patient presented to us with 2-month history of perineal irritation, dysuria, and nicturia.

- The diagnosis revealed a case of signet-ring cell mucinous adenocarcinoma of the prostate with massive local extension and a good response to biochemotherapy after bone skeletal progression.

- Here, we discuss the clinical features and therapy response, which were similar to those of metastatic colorectal carcinoma.

- Treatment with FOLFOX + Erbitux (after K-ras typing) seems to be effective (completely response) with acceptable treatment-related morbidity for this rare prostate cancer subtype.

\section{Keywords}

Adenocarcinoma; Cetuximab; Prostate; Signet ring cell 


\section{Introduction}

Carcinoma of the prostate gland is the most common visceral malignant tumor that affects men. ${ }^{1}$ Conventional acinar adenocarcinoma represents the majority ( $\left.>90 \%\right)$ of the tumors derived from the prostate gland. Uncommon variants (5\%-10\%) of prostatic adenocarcinoma are readily recognizable by their distinctive histologic features and are important because they might signify a worse clinical prognosis. ${ }^{2}$

Primary signet ring cell carcinomas (SRCC) of the prostate are extremely rare. As the name implies, the defining characteristic of the variant is the presence of signet ring cells, which are characterized by a crescent-shaped nucleus that is indented, displaced, and compressed against the cell membrane by a large, clear, cytoplasmic vacuole. ${ }^{2}$ Fewer than 60 patients with this rare malignancy have been described in the literature. SRCC of the prostate exhibits a median overall survival of 28 months from initial surgery, which implies a worse prognosis compared with standard adenocarcinomas. ${ }^{3}$

\section{Case Report}

A 65-year-old man with an Eastern Cooperative Oncology Group status of 0 at baseline and no relevant medical history visited the hospital due to a 2-month history of perineal irritation, dysuria, and nycturia. After digital rectal examination and sextant needle biopsy, the patient was diagnosed with low-differentiated mucinous adenocarcinoma; $>50 \%$ of the cells were signet ring cells (T3bN0M0). The Gleason grade was IX $(\mathrm{IV}+\mathrm{V})$. The carcinoma cells were positive for prostatespecific antigen (PSA), cytokeratin (CK) 20 (CK20), and alcian blue stain. CK5 and CK6 were negative. Levels of serum markers were as follows: PSA/soluble, $6.6 \mathrm{ng} / \mathrm{mL}$ (reference range, 0.0 $4.0 \mathrm{ng} / \mathrm{mL}$ ); PSA/free, $1.9 \mathrm{ng} / \mathrm{mL}$; PSA/complexed, $3.5 \mathrm{ng} / \mathrm{mL}$, PSA-free-PSA-soluble ratio, 0.29, and carcinoembryonic antigen (CEA), $3.40 \mathrm{ng} / \mathrm{mL}$ (reference range, 0.0-5.0 ng/mL). A wholebody computed tomography showed a partially calcified prostatic mass that infiltrated the trigonous and lateral bladder walls and probably the seminal vesicles. The prostatic mass induced bilateral obstructive uropathy. Magnetic resonance imaging of the prostate was performed, and a diffuse pattern was interpreted as generalized tumor infiltration of the whole gland, including both seminal vesicles. The patient also underwent a full workup, including colonoscopy and oral endoscopy, with biopsy specimens negative for neoplasia.

Five cycles of neoadjuvant prostate cancer common chemotherapy with docetaxel (docetaxel, $75 \mathrm{mg} / \mathrm{m}^{2}$ every 3 weeks plus prednisone $10 \mathrm{mg} / \mathrm{d}$ ) were administered before radical surgery. After systemic treatment, a minor response of the prostate gland was observed by magnetic resonance imaging (the normal rectal wall and the small prostate were completely separated from the rectum). The PSA level after chemotherapy was $\geq 4 \mathrm{ng} / \mathrm{mL}$, and was negative. The patient underwent radical cystoprostatectomy. Histologic examination of 1 section showed infiltration by a population of uniform, plump, mucus-containing cells with eccentrically compressed hyperchromatic nuclei, and positivity to periodic acid-Schiff and alcian blue stain (signet ring cells) (Figure 1). 

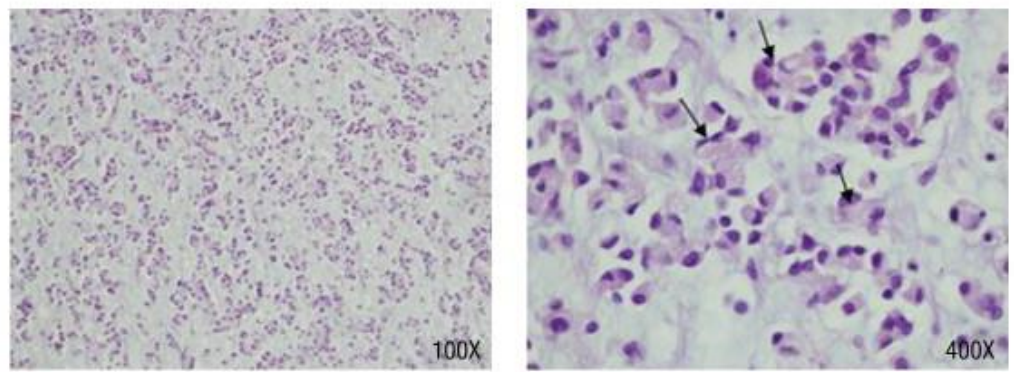

Figure 1. Sections that correspond to infiltrating adenocarcinoma of signet ring cells in the prostate (Hematoxylin and Eosin; original magnifications, $\times 100, \times 400$ )

After radical surgery, the patient had no evidence of disease and had a good quality of life. Over the next 8 months, the patient experienced diffuse bone pain and had elevated serum alkaline phosphatase levels. Serum PSA and prostatic acid phosphatase were negative, but CEA was positive $(859 \mathrm{ng} / \mathrm{mL})$. Serum testosterone levels were $44 \mathrm{ng} / \mathrm{mL}$ (limits, $241-827 \mathrm{ng} / \mathrm{mL}$ ). Bone scan scintigraphy revealed extensive skeletal involvement (Figure 2). A computed tomography did not show locoregional (nearby pelvic structures) or visceral and/or node involvement, but metastatic blastic lesions were observed on axial and appendicular bones.

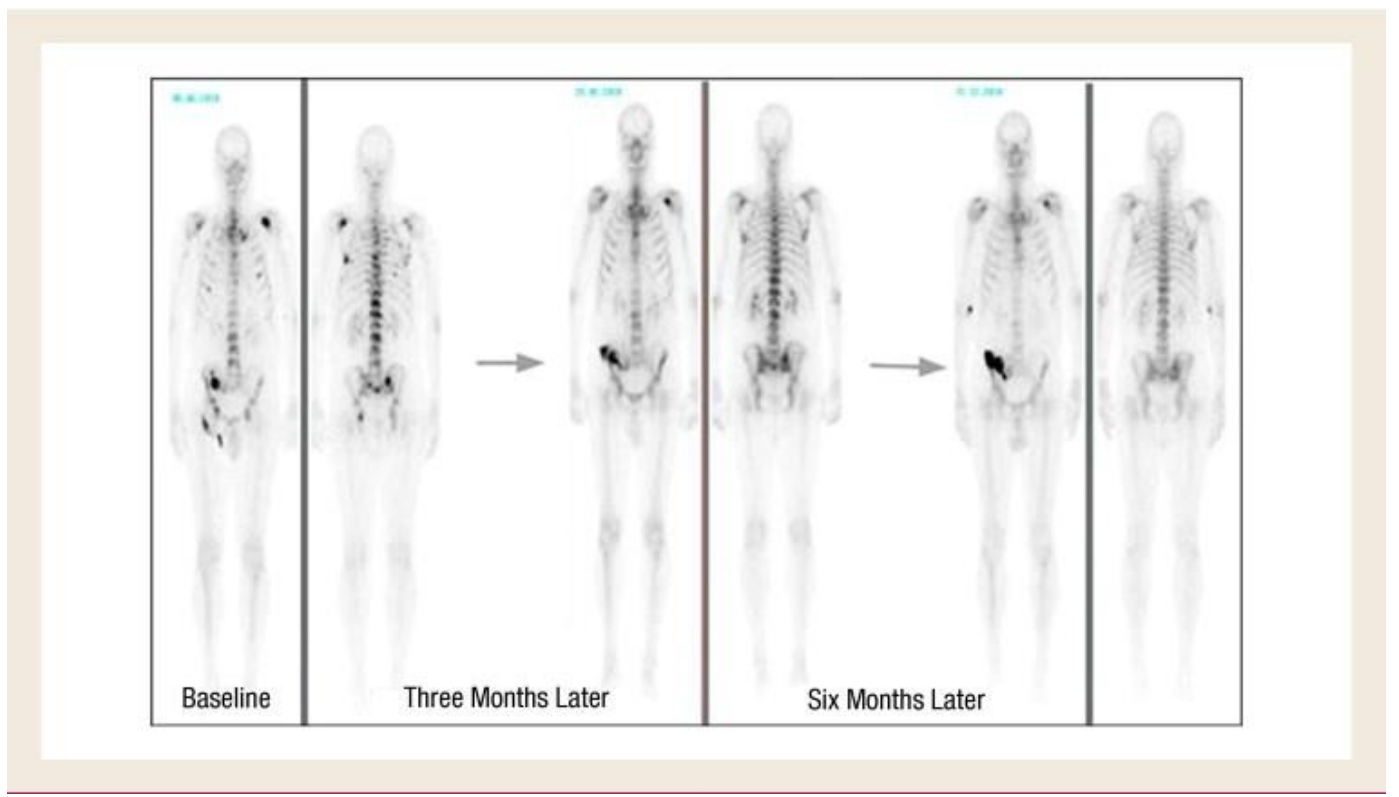

Figure 2. Evolution of metastatic bone disease after initiation of cytostatic treatment 
We assessed the mutational status for mutation of KRAS by polymerase chain reaction, which showed no mutation in exons 12 and 13, or 61, which are most commonly mutated in colorectal cancer. Based on this information, we decided to start systemic cytostatic treatment with FOLFOX (oxaliplatin $85 \mathrm{mg} / \mathrm{m}^{2}$ on day 1, plus leucovorin $200 \mathrm{mg} / \mathrm{m}^{2}$ and fluorouracil as a $400 \mathrm{mg} / \mathrm{m}^{2}$ bolus, followed by a $600 \mathrm{mg} / \mathrm{m}^{2}$ infusion during 22 hours on days 1 and 2) plus Erbitux $\left(500 \mathrm{mg} / \mathrm{m}^{2}\right.$ day $1)^{4}$; we obtained a partial response after 3 cycles and a complete response after 7 cycles, as determined by bone scan scintigraphy images (Figure 2). Therapy was discontinued due to peripheral neurotoxicity of oxaliplatin. Twelve months after the start of treatment, CEA levels had normalized $(<5 \mathrm{ng} / \mathrm{mL})$.

\section{Discussion}

Primary SRCC is a rare disease that was first described in 1985 and is estimated to occur in 30 of every 100,000 cases of prostate cancer. ${ }^{5}$ The diagnosis of primary prostatic SRCC requires that $25 \%$ or more of the tumor be composed of signet ring cells. ${ }^{6}$

There is a lack of data regarding the molecular etiology of signet ring cells. ${ }^{7}$ In signet ring cell adenocarcinomas of the colon, a higher frequency of BRAF mutations (22\% vs. 8.6\%) and a lower frequency of KRAS mutations were observed. ${ }^{8,9}$ Based on these data, the authors concluded that SRCCs might have a distinct mutation pattern with respect to the main growth kinase pathways. The higher incidence of this type of tumor in the digestive tract and the lack of activity when docetaxel-based chemotherapy was administered as neoadjuvant treatment compelled us to treat this patient from a molecular and histologic perspective rather than an organ-derived perspective.

Primary SRCCs of the prostate are very rare and have a poor prognosis even when treated with aggressive therapy. More of these patients present with stage IV disease than with any other stage. Patients in most of the reported cases received typical treatment for prostatic adenocarcinoma, including hormonal manipulation, surgery, radiation, or a combination. SRCC of the prostate rarely responds to hormonal manipulation. ${ }^{5}$ Elevation of PSA levels as a tumor marker for SRCC of the prostate has not been consistently observed in the literature. To the best of our knowledge, the present case is the first SRCC of the prostate to be treated with colorectal chemotherapy. This approach achieved a near-complete response and evident clinical benefit, as is shown in Figure 2.

In summary, treatment of SRCC of the prostate with FOLFOX plus cetuximab seems to be effective, with acceptable treatment-related morbidity for this rare prostate cancer subtype. The lack of clinical data in this setting is justified by the lower incidence of the disease, but cooperative organization, therefore, is mandatory. Adding molecular techniques to routine pathologic stains may orientate treatment according to druggable targets available in the market, this is critical for patient management, especially with rare and aggressive malignancies such as SRCC of the prostate.

\section{Disclosure}

The authors have stated that they have no conflicts of interest.

\section{Acknowledgment}

We would like to thank our colleague V. Medina Villaamil for exceptional assistance with this manuscript, including generation of figures. 


\section{References}

1. Zivi A, Massard C, De-Bono J. Changing therapeutic paradigms in castrate-resistant. prostate cancer.. Clin Genitourin Cancer. 2010; 8:17-22.

2. Berney DM, Montironi R, Egevad L. Pathology in prostate research: optimizing the. pathological data.. Acta Oncol. 2011; 50(suppl 1):49-52.

3. Kums JJ, van Helsdingen PJ. Signet-ring cell carcinoma of the bladder and the. prostate. Report of 4 cases.. Urol Int. 1985; 40:116-9.

4. Bokemeyer C, Bondarenko I, Makhson A, et al. Fluorouracil, leucovorin, and oxaliplatin with and without cetuximab in the first-line treatment of metastatic colorectal cancer.. J Clin Oncol. 2009; 27:663-71.

5. Warner JN, Nakamura LY, Pacelli A, et al. Primary signet ring cell carcinoma of the. prostate.. Mayo Clin Proc. 2010; 85:1130-6.

6. Remmele W, Weber A, Harding P. Primary signet-ring cell carcinoma of the prostate. Hum Pathol. 1988; 19:478-80.

7. Gopalan V, Smith RA, Ho YH, et al. Signet-ring cell carcinoma of colorectum:. current perspectives and molecular biology.. Int J Colorectal Dis. 2011; 26:127-33.

8. Ogino S, Brahmandam M, Cantor M, et al. Distinct molecular features of colorectal. carcinoma with signet ring cell component and colorectal carcinoma with mucinous. component.. Mod Pathol. 2006; 19:59-68.

9. Wistuba II, Behrens C, Albores-Saavedra J, et al. Distinct K-ras mutation pattern. characterizes signet ring cell colorectal carcinoma.. Clin Cancer Res. 2003; 9:3615-9 